\title{
The fate of the unexpected positive intraoperative cultures after revision total knee arthroplasty
}

\author{
Robert L. Barrack \\ Washington University \& Barnes-Jewish Hospital, St. Louis, MO \\ Ajay Aggarwal \\ Washington University \& Barnes-Jewish Hospital, St. Louis, MO \\ R. Stephen J. Burnett \\ Washington University \& Barnes-Jewish Hospital, St. Louis, MO \\ John C. Clohisy \\ Washington University \& Barnes-Jewish Hospital, St. Louis, MO \\ ElifroWhangemand additional works at: https://jdc.jefferson.edu/orthofp \\ Thomas Jefferson University \& Rothman Institute of Orthopaedics \\ Part of the Orthopedics Commons

\section{Let us know how access to this document benefits you}

\section{Recommended Citation}

Barrack, Robert L.; Aggarwal, Ajay ; Burnett, R. Stephen J.; Clohisy, John C.; Ghanem, Elie; Sharkey, Peter; and Parvizi, Javad, "The fate of the unexpected positive intraoperative cultures after revision total knee arthroplasty" (2007). Department of Orthopaedic Surgery Faculty Papers. Paper 6.

https://jdc.jefferson.edu/orthofp/6

This Article is brought to you for free and open access by the Jefferson Digital Commons. The Jefferson Digital Commons is a service of Thomas Jefferson University's Center for Teaching and Learning (CTL). The Commons is a showcase for Jefferson books and journals, peer-reviewed scholarly publications, unique historical collections from the University archives, and teaching tools. The Jefferson Digital Commons allows researchers and interested readers anywhere in the world to learn about and keep up to date with Jefferson scholarship. This article has been accepted for inclusion in Department of Orthopaedic Surgery Faculty Papers by an authorized administrator of the Jefferson Digital Commons. For more information, please contact: JeffersonDigitalCommons@jefferson.edu. 
Authors

Robert L. Barrack, Ajay Aggarwal, R. Stephen J. Burnett, John C. Clohisy, Elie Ghanem, Peter Sharkey, and Javad Parvizi 


\section{The Fate of the Unexpected Positive Intraoperative Cultures After Revision Total Knee Arthroplasty}

Robert L. Barrack, MD,* Ajay Aggarwal, MD,* R. Stephen J. Burnett, MD, FRCS(C),* John C. Clohisy, MD,* Elie Ghanem, MD, $\$$ Peter Sharkey, MD, $\$$ and Javad Parvizi, MD, FRCS $§$

From the *Department of Orthopaedic Surgery, Washington University School of Medicine, Barnes-Jewish Hospital, St Louis, Missouri; and §Thomas Jefferson University Medical School, Rothman Institute of Orthopaedics, Philadelphia, Pennsylvania.

\section{Abstract}

Of a consecutive series of 692 revision total knees at 3 centers, intraoperative cultures were unexpectedly found to be positive in 41 cases $(5.9 \%)$. Of the $41,29(71 \%)$ cases had a single positive intraoperative culture and were determined to be a probable false positive based on absence of any other evidence of infection, of which 5 were treated with extended course of intravenous antibiotics after hospital discharge and the remaining 24 received no further treatment. None of these 24 patients manifested any sign of infection at follow-up, averaging 46 months (range, 24-74 months). Twelve patients were determined to have probable type 1 periprosthetic infection, 11 of which were treated with a course of antibiotics. Two of these patients became reinfected within a year. A single positive intraoperative culture after revision total knee arthroplasty does not mandate further treatment in the absence of any other signs of infection.

Key words: revision total knee arthroplasty, knee, TKA, infection, positive intraoperative culture, aseptic.

The results of intraoperative cultures have traditionally been considered as the gold standard in the diagnosis of periprosthetic infection $[1,2]$ Gollwitzer et al [3] however stated that "The real accuracy of intraoperative culture and permanent histology cannot be determined due to the missing gold standard." The reported incidence of false-positive cultures in revision total joint arthroplasty has been extremely variable, ranging from $3 \%$ to $52 \%$ and averaging more than $20 \%$ in the recent literature (Table 1 ). The relative inaccuracy of these results lead one 
author to coin the term tarnished gold standard in referring to the role of intraoperative cultures in establishing the diagnosis of periprosthetic infection [14]. Limited data are currently available on the clinical outcome of cases in which intraoperative cultures are unexpectedly positive after a total knee arthroplasty (TKA) revision has been undertaken. One possibility in this scenario is that the preoperative tests represented falsenegative results and the intraoperative culture is a true positive. This would represent a type 1 periprosthetic infection as described by Segawa et al [15], Tsukayama et al [16], and Leone and Hanssen [17]. In these cases, a course of 4 to 6 weeks of antibiotics is generally recommended with a high success rate generally reported $[15,16,18]$. Type 1 infections are relatively rare, constituting only $5(6 \%)$ of 81 infections in the original series reported by Segawa et al [15] and $16(3 \%)$ of 509 periprosthetic infections at the Mayo Clinic over a 4-year period as reported by Marculescu et al [18] (Table 2) Much more commonly, based on previous reports, is that the intraoperative culture result represents a false positive (Table 1). We report the outcome of a consecutive series of unexpected positive intraoperative cultures in revision TKA surgery from 3 centers, both those determined to be probable true positives (type 1 periprosthetic infections) as well as those determined to be probable false positives.

\section{Materials and Methods}

All revision TKA cases performed on the total joint services of 1 of 3 university-affiliated referral hospitals were reviewed. A database was maintained at each center that prospectively tracked all revision patients. Charts were reviewed to obtain complete details on preoperative testing, intraoperative findings, and postoperative clinical follow-up. The data that were obtained routinely included erythrocyte sedimentation rate (ESR), in most cases a C-reactive protein (CRP), and white blood cell count. Preoperative aspiration was performed routinely at 1 center and selectively at the other 2 centers. When successful aspiration was performed, results of aerobic and anaerobic cultures were recorded both from solid media and enhanced liquid media (broth). In cases where cultures were positive on enhanced culture media ("broth only"), this was noted. Cultures for fungus and acid-fast bacteria were not included in this analysis. When sufficient fluid was obtained, a differential cell count was performed. The number of nucleated cells was recorded as well as the percentage of polymorphonuclear cells (PMNs). A culture of joint fluid was obtained in every case in addition to at least 1 culture of tissue from behind the implants in all but 3 cases. Cultures from the canals were not routinely obtained. Intraoperative culture results were documented. The organism that was identified and whether growth occurred on solid media

This is the authors' final version prior to publication in The Journal of Arthroplasty 22(6, Suppl. 1): 94-99, September 2007. The published version is available at http://dx.doi.org/10.1016/j.arth.2007.03.029, copyright (C) by Elsevier, Inc. 
or broth only were recorded. The length of clinical follow-up was also recorded in months and whether or not any sign of infection or surgical treatment manifested during clinical follow-up was noted. The method of treatment of the positive intraoperative culture was also documented.

Cases were retrospectively classified as type 1 infections based on the following criteria: presence of the same organism on 2 cultures as described by Segawa et al [15] and Leone and Hanssen [17], or growth on solid media of an organism in conjunction with other objective evidence of infection such as presence of an elevated sedimentation rate and/or CRP in the absence of inflammatory disease or presence of a joint aspirate that was suspicious for infection (cell count $>2500$ and/or percentage of PMNs $>70 \%)$. A variable number of cultures were obtained, most commonly 2 or 3 (mean, 2.5; range, 1-8). Intraoperative culture results were classified as probable false positives if there were less than 2 positive cultures or if a single positive culture occurred in the absence of other objective signs of infection as described above.

\section{Results}

Eight-hundred eighty-nine consecutive revision TKAs were performed during a 6-year period. One hundred ninety-seven were classified as infected based on the criteria defined by Leone and Hanssen [17] including growth of the same organism in 2 or more cultures of specimens obtained by aspiration or deep tissue specimens at surgery, finding of acute inflammation histologically, gross purulence at the time of surgery, and/or an actively draining sinus. These cases were treated with a component removal and insertion of an antibiotic spacer with subsequent reimplantation or knee fusion. Six-hundred ninety-two cases were classified as not infected based on clinical and laboratory criteria and were treated with revision TKA. In 41 (5.9\%) of 692 cases, a postoperative culture result was subsequently discovered to be positive after revision TKA. In 29 cases, there was a single positive culture with no other evidence of infection and these were therefore classified as probable false-positive results (Table 3 ). Twenty-four (83\%) of these cases were managed with no treatment other than prophylactic antibiotics, which were discontinued before hospital discharge. Clinical follow-up averaged 45 months (24-74 months). Five were treated with a 4-to 6-week course of antibiotics usually based primarily on recommendations of infectious disease consultants. No patient in this group manifested signs of infection or had any further surgical procedures. 
The remaining 12 showed some sign of infection based on preoperative or intraoperative findings including 2 positive cultures of the same organism (8) and/or a single positive culture on solid media and an abnormal ESR $(\geq 30)$, CRP $(\geq 5)$, or preoperative aspirate (Table 4$)$. All but 1 of these cases were treated with a 4-to 6-week course of antibiotics. There were 2 early recurrent infections (within 12 months) in this group, both of which had received a 6-week course of antibiotics and both were treated with 2stage exchange. One patient in this group underwent revision for aseptic loosening at 72 months, at which point all intraoperative cultures were negative and there were no signs of infection perioperatively or at the follow-up of that single case.

\section{Discussion}


Although intraoperative cultures have been referred to as the gold standard for establishing the presence of periprosthetic infection, the exact method of obtaining and interpreting these culture results is not agreed upon. Segawa et al originally described the establishment of infection after revision TKA based on the subsequent finding of a positive intraoperative culture. This was subsequently termed a type 1 deep periprosthetic infection with the other types being early postoperative infection (type 2), acute hematogenous infection (type 3), and late chronic infection (type 4) $[15,17]$. They required, however, the presence of 2 or more positive cultures and specifically did not consider a single positive culture as adequate evidence of infection and disregarded cultures that were positive in broth only [15]. They successfully treated 5 of 5 type 1 infections with 6 weeks of antibiotics and their reported incidence of type 1 infections was relatively low (5/81, 6\%). Marculescu et al reported on $16(3 \%)$ type 1 infections of a total of 509 infected total hips and total knees with successful treatment with antibiotics alone in 15 of 16 , although 2 patients did not receive postoperative antibiotics aside from routine prophylaxis [18]. In a follow-up study of Segawa et al [15], Tsukayama et al [16] reported on a higher number and percentage of infected total hip cases diagnosed based on intraoperative cultures subsequent to revision $(31 / 275,11 \%)$ with successful treatment of 28 $(90 \%)$ of 31 with antibiotics alone. It should be noted, however, that in only 1 of 25 cases in which histology was performed was evidence of acute inflammation demonstrated. Some of these cases could well have been false-positive intraoperative cultures in spite of the presence of 2 positive culture results. Kamme and Lindberg [12], in fact, defined the presence of 1 or 2 positive cultures out of 5 as representative of probable contaminants and suggested 3 positive cultures out of 5 as the threshold for defining infection. In a large consortium study, Atkins et al agreed with 3 of 5 positive intraoperative cultures as the recommended threshold for defining infection and reported that when only 2 of 5 cultures were positive, infection was present in only $25 \%$ of cases. Even these criteria were not foolproof, however. When 5 cultures were obtained, there was a $1 \%$ chance that all 5 would be negative in an infected case and an $8 \%$ chance that only 1 of the 5 cultures would be positive in an infected case [19]. The report by Atkins et al [19] included both hip and knee revisions, whereas that of Kamme and Lindberg [12] included only hip revisions. Mikkelsen et al [20] applied the Kamme and Lindberg [12] criteria ( $\geq 3$ of 5 positive intraoperative cultures) to a series of 120 total knee revisions, of which 26 were classified as infected, 58 as aseptically loose, and 36 with mechanical problems based on data available before revision [20]. When the mechanical problem group was excluded, the sensitivity, specificity, positive predictive value, and negative predictive values were

This is the authors' final version prior to publication in The Journal of Arthroplasty 22(6, Suppl. 1): 94-99, September 2007. The published version is available at http://dx.doi.org/10.1016/j.arth.2007.03.029, copyright (C) by Elsevier, Inc. 
$46 \%, 100 \%, 100 \%$, and $81 \%$, respectively. The relatively low sensitivity and negative predictive values were noted as signifying the need for new diagnostic methods. This supports the concept of considering objective measures other than culture results, as was done in this study.

In addition to the criteria discussed above, numerous other definitions of infection based on intraoperative culture results have been suggested including growth on 1 solid media culture, 2 liquid media cultures, 1 aspirate culture plus 1 intraoperative culture, or 4 of 5,5 of 5 , or 5 of 6 intraoperative cultures $[6,12,17,21-24]$. Clearly, there is no consensus for the establishment of the presence of total knee infection based on intraoperative culture results alone. The strong trend in the literature is to recommend obtaining multiple intraoperative samples, generally 4 to 6 . In the current study, only 2 or 3 cultures were obtained in most cases. This was a select group of patients though in that none was thought to be infected at the time of surgery as evidenced by the fact that a revision procedure was performed. Single-stage exchanges were not performed at any of the 3 centers during the course of this study, so if infection was suspected based on preoperative or intraoperative findings, component resection would have been performed. Atkins et al [19] noted the tendency to submit fewer cultures when wounds appeared benign and less likely to be infected in the surgeon's view. They, in fact, noted that when more cultures were submitted, infection was more likely to be present. This is reflected in this study because an average of 2.5 cultures were submitted in cases classified as probably not infected compared with 3.8 cultures in those classified as probable type 1 infections.

In spite of the general trend toward obtaining numerous intraoperative cultures, it is still common practice to obtain a lesser number of cultures or even a single culture during routine revision cases especially when the index of suspicion is low based on intraoperative appearance and preoperative testing as in most cases in the present series. The interpretation of 3 or fewer intraoperative cultures can be fraught with difficulty. In the present study, most of these results were classified as probable false positives based on the absence of other evidence of infection and growth on broth only or growth on solid media classified as rare ( $<10$ colonies in a single quadrant) usually of a low virulence organism. Growth of at least 5 colonies on solid media has been suggested as a threshold for considering a culture a true positive [25]. It cannot be determined how many cases in the present study had fewer than 5 colonies on their solid media cultures as these data are not routinely maintained long term on the databases of the laboratories in this study.

This is the authors' final version prior to publication in The Journal of Arthroplasty 22(6, Suppl. 1): 94-99, September 2007. The published version is available at http://dx.doi.org/10.1016/j.arth.2007.03.029, copyright @ by Elsevier, Inc. 
Of $41,29(71 \%)$ of positive cultures were classified as false positives using these arbitrary criteria. This would represent an overall $4.2 \%$ $(29 / 692)$ incidence of false-positive cultures, which is actually lower than previously reported (Table 1 ). Although most reports have focused on revision hip rather than revision knee and false positives seem to be more common after hip revision than after knee revision. Of 29 cases, 24 were not treated with antibiotics after hospital discharge, whereas 5 were treated based on recommendation of consultants and/or preference of the surgeon. None of these cases manifested signs of infection at follow-up averaging 45 months (range, 24-74 months). These results indicate that not all positive intraoperative cultures require treatment. Certainly, a 4-to 6 -week course of antibiotics, either intravenous or oral, entails a degree of risk and cost that would not be justified on a routine basis based on these results.

Twelve cases in this series were retrospectively classified as type 1 infections based on growth on solid media and other evidence of infection such as elevated ESR or elevated cell count or percentage of PMNs in the joint aspirate. This represented $6.1 \%(12 / 197)$ of infected total knees during this period, similar to previous reports of type 1 periprosthetic infections (Table 2). All but 1 of these cases were treated with a course of postoperative antibiotics. Of the 12 cases, 2 developed early postoperative infections within the first 12 months after revision, leading to resection arthroplasty. Both had been treated with a course of intravenous antibiotics after hospital discharge. One of the two, however, demonstrated a different organism than the intraoperative culture so this could represent a de novo infection rather than a treatment failure. The success rate $(10 / 12)$ is similar to previous reports $[15,16,18]$, but with the low numbers available, the results are difficult to interpret. Compromised hosts, virulent organisms, or both could explain failure of antibiotics alone to eradicate an occult infection discovered postoperatively.

One strength of this study is the size of the sample. By combining data from 3 referral centers, we were able to obtain data on almost 700 revision knees, which is one of the largest series in the literature. Because the incidence of unexpected false-positive cultures is relatively low, it is necessary to have a very large sample size to be able to make any comment on the fate of the unexpected false-positive cultures, which was the object of this study. A weakness of this study, however, is that the protocol for culturing knees was not agreed upon prospectively. There was lack of standardized technique of culture such as a number of cultures to obtain and the exact sites from which to obtain cultures, which weakens the data to some degree.

This is the authors' final version prior to publication in The Journal of Arthroplasty 22(6, Suppl. 1): 94-99, September 2007. The published version is available at http://dx.doi.org/10.1016/j.arth.2007.03.029, copyright @ by Elsevier, Inc. 


\section{Conclusion}

The results of the present study indicate that intraoperative cultures do have limitations, consistent with many previous studies. This points to the importance of considering additional data in arriving at a diagnosis. We would therefore recommend routinely obtaining an ESR, CRP, and preoperative aspiration for culture, cell count, and differential cell count. If the preoperative ESR, CRP, aspiration cell count, or differential cell count is abnormal or intraoperative tissue appearance is suggestive of possible infection, multiple cultures (five or more) as well as frozen section and permanent histology are advisable. The results of the present study, however, indicate that treatment of a single positive intraoperative is not necessary in the absence of any other evidence of infection.

\section{References}

1. SpangehI MJ, Masri BA, O'Connell JX, et al. Prospective analysis of preoperative and intraoperative investigations for the diagnosis of infection at the sites of two hundred and two revision total hip arthroplasties. J Bone Joint Surg Am 1999;81:672.

2. Della Valle CJ, Zuckerman JD, Di Cesare PE. Periprosthetic sepsis. Clin Orthop Relat Res 2004:26.

3. Gollwitzer H, Diehl P, Gerdesmeyer L, et al. Diagnostic strategies in cases of suspected periprosthetic infection of the knee: a review of the literature and current recommendations. Orthopade $2006 ; 35: 904$.

4. Fehring TK, McAlister Jr JA. Frozen histologic section as a guide to sepsis in revision joint arthroplasty. Clin Orthop Relat Res 1994;304:229.

5. Lonner JH, Desai P, Dicesare PE, et al. The reliability of analysis of intraoperative frozen sections for identifying active infection during revision hip or knee arthroplasty. J Bone Joint Surg Am $1996 ; 78: 1553$.

6. Athanasou NA, Pandey R, De Steiger R, et al. Diagnosis of infection by frozen section during revision arthroplasty. J Bone Joint Surg $\mathrm{Br}$ 
1995;77B:28.

7. Padgett DE, Silverman A, Sachjowicz F, et al. Efficacy of intraoperative cultures obtained during revision total hip arthroplasty. J Arthroplasty 1995;10:420.

8. Barrack RL, Harris WH. The value of aspiration of the hip joint before revision total hip arthroplasty. J Bone Joint Surg Am $1993 ; 75: 66$.

9. Lachiewicz PF, Rogers GD, Thomason HC. Aspiration of the hip joint before revision total hip arthroplasty. Clinical and laboratory factors influencing attainment of a positive culture. J Bone Joint Surg Am 1996;78: 749.

10. Duff GP, Lachiewicz PF, Kelley SS. Aspiration of the knee joint before revision arthroplasty. Clin Orthop Relat Res 1996;331:132.

11. Mirra JM, Marder RA, Armstutz HC. The pathology of failed total joint arthroplasty. Clin Orthop Relat Res 1982;170:175.

12. Kamme C, Lindberg L. Aerobic and anaerobic bacteria in deep infections after total hip arthroplasty: differential diagnosis between infectious and non-infectious loosening. Clin Orthop Relat Res 1981:201.

13. Buchholz HW, Elson RA, Engelbrecht $E$, et al. Management of deep infection of total hip replacement. J Bone Joint Surg Am $1981 ; 63 B: 342$.

14. Bauer TW, Parvizi J, Kobayashi N, et al. Diagnosis of periprosthetic infection. J Bone Joint Surg Am 2006; 88:869.

15. Segawa H, Tsukayama DT, Kyle RF, et al. Infection after total knee arthroplasty. A retrospective study of the treatment of eighty-one infections. J Bone Joint Surg Am 1999;81:1434.

16. Tsukayama DT, Estrada R, Gustilo RB. Infection after total hip arthroplasty. A study of the treatment of one hundred and six infections. J Bone Joint Surg Am 1996;78:512.

17. Leone JM, Hanssen AD. Management of infection at the site of a total knee arthroplasty. Instr Course Lect 2006;55:449. 
18. MarculescuCE, Berbari EF, Hanssen AD, et al. Prosthetic joint infection diagnosed postoperatively by intraoperative culture. Clin Orthop Relat Res 2005;439:38.

19. Atkins BL, Athanasou N, Deeks JJ, et al. Prospective evaluation of criteria for microbiological diagnosis of prosthetic-joint infection at revision arthroplasty. The OSIRIS Collaborative Study Group. J Clin Microbiol 1998;36:2932.

20. Mikkelsen DB, Pedersen C, Hojbjerg T, et al. Culture of multiple peroperative biopsies and diagnosis of infected knee arthroplasties. APMIS 2006;114:449.

21. Cuckler JM, Star AM, Alavi A, et al. Diagnosis and management of the infected total joint arthroplasty. Orthop Clin North Am $1991 ; 22: 523$.

22. Garvin KL, Hanssen AD. Current concepts review: infection after total hip arthroplasty. J Bone Joint Surg Br 1995;77A:1576.

23. Kristinsson KG, Hope PG, Norman $P$, et al. Deep infections associated with total hip arthroplasties caused by coagulase negative staphylococci-pathogenesis and microbial diagnosis. J Bone Joint Surg Br 1989;71:329.

24. Steckelberg JM, Osmon DR. Prosthetic joint infections. In: Bisno $A L$, Waldvogel FA, editors. Infections associated with indwelling medical devices. 2nd ed. Washington, (DC): American Society for Microbiology; 1994. p. 259.

25. Dietz FR, Koontz FP, Found EM, et al. The importance of positive bacterial cultures of specimens obtained during clean orthopaedic operations. J Bone Joint Surg Am 1991;73:1200. 


\section{TABLES \& FIGURES}

\section{Table 1. Incidence of False-Positive Intraoperative Cultures for Periprosthetic Infection}

\begin{tabular}{lll}
\hline Author (Reference) & False Positive/Total & Study Group \\
& & \\
\hline $\begin{array}{l}\text { Fehring and McAlister [4] } \\
\text { Lonner et al [5] }\end{array}$ & $5 / 86(6 \%)$ & Revision hip \\
knee & $7 / 19(37 \%)$ & Revision hip and \\
Athanasou et al [6] & $3 / 84(4 \%)$ & Revision hip and \\
knee & $43 / 142(30 \%)$ & Revision hip \\
Padgett et al [7] & $54 / 260(21 \%)$ & Revision hip \\
Barrack and Harris [8] & $2 / 21(10 \%)$ & Revision hip \\
Lachlewicz et al [9] & $1 / 19(6 \%)$ & Revision knee \\
Duff et al [10] & $5 / 27(19 \%)$ & Revision hip and \\
Mirra et al [11] & $10 / 31(32 \%)$ & Primary hip \\
knee & $13 / 25(52 \%)$ & Revision hip \\
Kamme and Lindberg [12] & $80 / 667(12 \%)$ & Revision hip \\
Kamme and Lindberg [12] & $6 / 180(3 \%)$ & Revision hip \\
Bucholz et al [13] & & \\
Spangehl et al [1] & $229 / 960(24 \%)$ & \\
Total & & \\
\hline
\end{tabular}

Patients on antibiotics excluded.

\section{Table 2. Results of Treating Type 1 Periprosthetic Infections With Antibiotics} Alone

\begin{tabular}{|c|c|c|}
\hline $\begin{array}{l}\text { Author } \\
\text { (Reference) }\end{array}$ & $\begin{array}{l}\text { Success } \\
\text { Rate }\end{array}$ & $\begin{array}{l}\text { Percentage of } \\
\text { Infections } \\
\text { That Were Type } 1\end{array}$ \\
\hline $\begin{array}{l}\text { Segawa } \\
\text { et al [15] }\end{array}$ & $5 / 5$ (100\%) & $\begin{array}{l}5 / 81(6 \%) \text { infected } \\
\text { TKA }\end{array}$ \\
\hline Tsukayama & $28 / 31(90 \%)$ & $\begin{array}{l}31 / 275(11 \%) \\
\text { infected }\end{array}$ \\
\hline et al [16] & & THA cases \\
\hline $\begin{array}{l}\text { Marculescu } \\
\text { et al [18] }\end{array}$ & $15 / 16(94 \%)$ & $\begin{array}{l}\text { 16/509 (3\%) } \\
\text { infected THA } \\
\text { and TKA }\end{array}$ \\
\hline Total & 48/52 (92\%) & $52 / 865(6 \%)$ \\
\hline
\end{tabular}

Of 16,14 treated with antibiotics. 
Table 3. Summary of False-Positive Intraoperative Culture Cases

\begin{tabular}{|c|c|c|c|c|c|c|c|c|c|c|}
\hline Case & $\begin{array}{l}\text { Preop } \\
\text { ESR }\end{array}$ & $\begin{array}{l}\text { Preoperative } \\
\text { CRP }\end{array}$ & $\begin{array}{l}\text { Preoperative } \\
\text { WBC count }\end{array}$ & $\begin{array}{l}\text { Preoperative } \\
\text { Asp Nuc. } \\
\text { Cells }\end{array}$ & $\begin{array}{c}\text { Preoperative } \\
\text { Asp } \\
\% \text { PMNs } \\
\text { Neutrophils }\end{array}$ & $\begin{array}{c}\text { Intraoperative } \\
\text { Culture Organism }\end{array}$ & $\begin{array}{l}\text { Broth } \\
\text { Only }\end{array}$ & $\begin{array}{l}\text { No. of } \\
\text { Cultures }\end{array}$ & $\begin{array}{l}\text { Length of } \\
\text { Follow-Up } \\
\quad(\mathrm{mo})\end{array}$ & $\begin{array}{l}\text { Antibiotic } \\
\text { Treatment }\end{array}$ \\
\hline 1 & 7 & & 8.1 & 1940 & 25 & Enterococcus & Yes & 3 & 72 & No \\
\hline 2 & 10 & & 8.1 & 3 & 6 & $\begin{array}{l}\text { Staphylococcus } \\
\text { epidermidis }\end{array}$ & Yes & 3 & 66 & No \\
\hline 3 & 5 & & 7.2 & 29 & 2 & $\begin{array}{c}\text { Staphylococcus } \\
\text { aureus }\end{array}$ & Yes & 2 & 64 & No \\
\hline 4 & 10 & & 6.8 & 200 & 31 & Corynebacterium & No & 2 & 54 & No \\
\hline 5 & 5 & 0.2 & 8.1 & 2 & 5 & Diptheroids & No & 3 & 58 & No \\
\hline 6 & 10 & 0.3 & 7.1 & 30 & 0 & Streptococcus & No & 3 & 60 & No \\
\hline 7 & 16 & & 8.8 & 710 & 40 & S epidermidis & No & 2 & 44 & No \\
\hline 8 & 21 & 0.9 & 6.4 & 427 & 15 & $S$ aureus & No & 2 & 28 & Yes \\
\hline 9 & 24 & 1.2 & 5.7 & 200 & 29 & S epidermidis & No & 3 & 32 & No \\
\hline 10 & 8 & 2.2 & 5.7 & 765 & 24 & S aureus & No & 2 & 36 & Yes \\
\hline 11 & 13 & 0.8 & 12.2 & 360 & 10 & S epidermidis & No & 2 & 64 & No \\
\hline 12 & 19 & 4.0 & 7.6 & 140 & NA & $S$ epidermidis & Yes & 2 & 30 & No \\
\hline 13 & 12 & 1.1 & 4.2 & NA & NA & S epidermidis & Yes & 3 & 42 & No \\
\hline 14 & 3 & 0.4 & 4.2 & NA & NA & Streptococcus & Yes & 2 & 36 & No \\
\hline 15 & 22 & 2.2 & 10.1 & NSF & NSF & $\begin{array}{l}\text { Streptococcus } \\
\text { viridans }\end{array}$ & No & 5 & 66 & Yes \\
\hline 16 & 8 & 0.1 & 5.6 & NSF & NSF & S epidermidis & No & 4 & 24 & No \\
\hline 17 & 26 & 0.7 & 5.2 & NSF & NSF & $S$ epidermidis & Yes & 3 & 24 & No \\
\hline 18 & 63 & 5.2 & 6.8 & NSF & NSF & $S$ aureus & Yes & 2 & 26 & No \\
\hline 19 & 64 & 5.4 & 8.5 & 75 & 11 & S epidermidis & Yes & 6 & 24 & No \\
\hline 20 & 10 & 0.3 & 9.9 & NA & NA & S epidermidis & Yes & 2 & 68 & No \\
\hline 21 & 5 & & 9.3 & NA & NA & $S$ epidermidis & Yes & 1 & 56 & No \\
\hline 22 & 8 & 0.5 & 6.9 & NA & NA & S epidermidis & No & 4 & 40 & No \\
\hline 23 & 18 & 0.5 & 6.9 & NA & NA & Enterococcus & Yes & 2 & 35 & No \\
\hline 24 & 1 & & 6.6 & NA & NA & S epidermidis & Yes & 1 & 34 & No \\
\hline 25 & 12 & & 7.3 & NA & NA & Enterococcus & Yes & 2 & 28 & Yes \\
\hline 26 & 22 & 0.5 & 4.3 & NA & NA & S epidermidis & No & 1 & 24 & No \\
\hline 27 & 5 & 1.2 & 6.2 & 1200 & 24 & Diptheroids & No & 2 & 66 & No \\
\hline 28 & 14 & 0.8 & 5.8 & 420 & 18 & Corynebacterium & No & 2 & 74 & No \\
\hline 29 & 24 & 1.8 & 5.8 & 300 & 12 & Proprionobacter & Yes & 2 & 58 & Yes \\
\hline
\end{tabular}



Average
20.2
1.7
7.1
706
24
acnes
2.5
45

WBC indicates white blood cell; Asp Nuc. cells, number of nucleated cells on preoperative aspiration; Asp \% PMNs, preoperative aspiration percentage of PMNs; NSF, not sufficient fluid (culture-negative, inadequate volume for cell count/differential); NA, aspiration not performed.

\section{Table 4. Summary of Type 1 Periprosthetic Infection Cases}

\begin{tabular}{|c|c|c|c|c|c|c|c|c|c|c|}
\hline & $\begin{array}{c}\text { Preoperative } \\
\text { ESR }\end{array}$ & $\begin{array}{c}\text { Preoperative } \\
\text { CRP }\end{array}$ & $\begin{array}{l}\text { Preoperative } \\
\text { WBC count }\end{array}$ & $\begin{array}{l}\text { Preoperative } \\
\text { Asp Nuc. } \\
\text { Cells }\end{array}$ & $\begin{array}{c}\text { Preoperative } \\
\text { Asp \% } \\
\text { PMNs }\end{array}$ & $\begin{array}{c}\text { Intraoperative } \\
\text { Culture } \\
\text { Organism }\end{array}$ & $\begin{array}{l}\text { Broth } \\
\text { Only }\end{array}$ & $\begin{array}{l}\text { No. of } \\
\text { Cultures }\end{array}$ & $\begin{array}{l}\text { Length of } \\
\text { Follow-Up } \\
\text { (mo) }\end{array}$ & Complication \\
\hline 1 & 31 & 8.2 & 7.8 & NSF & & Enterococcus & No & 6 & 44 & \\
\hline 2 & 53 & 0.9 & 8.6 & 1500 & 82 & $S$ aureus & No & 8 & 24 & \\
\hline 3 & 12 & 4.5 & 6.9 & NSF & & S epidermidis & No & 5 & 24 & \\
\hline 4 & 1 & & 6.9 & 100 & 14 & $\begin{array}{l}\text { Sepidermidis } \\
\text { and } \\
\text { Enterococcus }\end{array}$ & No & 4 & & Reinfected \\
\hline 5 & 25 & 0.7 & 7 & NA & & Enterococcus & No & 2 & 40 & \\
\hline 6 & 78 & 0.7 & 8.4 & NA & & S epidermidis & No & 3 & 24 & \\
\hline 7 & 69 & 1.2 & 6.1 & NA & & MRSE & No & 2 & & Reinfected \\
\hline 8 & 28 & 2.4 & 8.1 & 4600 & 82 & S epidermidis & No & 3 & 72 & \\
\hline 9 & 84 & & 10.7 & NSF & & Enterococcus & Yes & 4 & 75 & \\
\hline 10 & 10 & 0.5 & 8.7 & NSF & & S epidermidis & No & 4 & 72 & $\begin{array}{l}\text { Revised- } \\
\text { loose }\end{array}$ \\
\hline 11 & 42 & 2.2 & 6.9 & NSF & & S epidermidis & Yes & 3 & 75 & \\
\hline 12 & 24 & 1.9 & 7.6 & NSF & & $\begin{array}{l}\text { S epidermidis } \\
\text { and } \\
\text { Streptococcus }\end{array}$ & Yes & 2 & 54 & \\
\hline Average & 38.1 & 2.3 & 7.8 & 2067 & 59 & & & 3.8 & 61.7 & \\
\hline
\end{tabular}

This is the authors' final version prior to publication in The Journal of Arthroplasty 22(6, Suppl. 1): 94-99, September 2007. The published version is available at http://dx.doi.org/10.1016/j.arth.2007.03.029, copyright ( $)$ by Elsevier, Inc. 